\title{
El Decreto Ejecutivo No. 35595-S y las implicaciones jurídico- sanitarias de los medicamentos de libre venta en Costa Rica
}

Executive Order No. 35595-S on over the counter medicines and its legal and sanitary implications in Costa Rica.

\section{Randall Madrigal Madrigal}

Abogado, Profesor de las Facultades de Farmacia de la Universidad de Costa Rica (UCR) y de la Universidad de Ciencias Médicas (UCIMED). Jefe del Departamento Jurídico del Colegio de Farmacéuticos de Costa Rica. San José, Costa Rica.

Palabras clave: Medicamentos de libre venta; establecimientos farmacéuticos; potestad reglamentaria.

Key-words: Over the counter medicines; Pharmacy; rule-maker power.

En el ordenamiento jurídico sanitario costarricense se reconoce una única definición de medicamento, que se encuentra en el numeral 104 de la Ley General de Salud de Costa Rica (Costa Rica, 1978). Lo cierto es que, a partir de la lectura armónica de algunos de sus artículos, puede distinguirse entre los medicamentos de prescripción, o de venta bajo receta médica, y aquellos denominados de libre venta.

Procedemos al enunciado de algunos artículos de la Ley General de Salud costarricense, entre ellos el artículo 120 que preceptúa: "Son de venta libre los medicamentos que el Ministerio declare como tales en el correspondiente decreto, oyendo previamente el criterio del Colegio de Farmacéuticos. En el caso de medicamentos para uso veterinario será también consultado el Colegio de Médicos Veterinarios."

El artículo de previa cita nos permite concluir que el legislador dispuso que el Poder Ejecutivo, vía reglamento, determinara, oyendo el criterio experto de instancias calificadas como los colegios de Farmacéuticos y de Médicos Veterinarios, cuáles medicamentos podrían ser considerados de libre venta, connotación esta última que demanda de un cuidadoso análisis para determinar su alcance.

Para ello, es de rigor citar el numeral 101 de la Ley General de Salud, que establece: "La elaboración, manipulación, venta, expendio, suministro y depósito de 
los medicamentos sólo podrán hacerse en establecimientos farmacéuticos debidamente autorizados y registrados".

La norma antes citada establece con claridad que solo en establecimientos farmacéuticos debidamente autorizados y registrados se podrá dar la elaboración, manipulación, venta, expendio, suministro y depósito de los medicamentos.

Es la misma Ley General de Salud, la que, en su numeral 95, se ocupa de definir los establecimientos farmacéuticos, señalando, con respecto a la farmacia, que se trata de "aquel que se dedica a la preparación de recetas y al expendio y suministro directo al público de medicamentos". Entre tanto, sobre los botiquines indica: "el pequeño establecimiento destinado, en forma restringida, únicamente al suministro de medicamentos que el Ministerio autorice, oyendo previamente el criterio del Colegio de Farmacéuticos. En el caso de medicamentos para uso veterinario, será necesario además, oír previamente el criterio del Colegio de Médicos Veterinarios".

Bien puede señalarse, a nuestro juicio, que no existe otra conclusión más que los establecimientos farmacéuticos, claramente definidos en el numeral 95 de la Ley General de Salud, son los únicos establecimientos en los que se puede elaborar, manipular, vender, expender, suministrar y depositar medicamentos, de tal forma que los medicamentos de venta libre - pues no escapan de la categoría de medicamentos - únicamente pueden ser ofrecidos al consumidor en establecimientos farmacéuticos debidamente autorizados para tal fin. Para el caso que nos ocupa, en la farmacia y en el botiquín, de tal forma que libre venta implica que no requieren de receta médica, no así que puedan ser ofrecidos en cualquier establecimiento comercial.

No obstante lo anterior, el Decreto Ejecutivo No. 35595-S, del 16 de setiembre de 2009, denominado "Declara Medicamentos de Venta Libre al Consumidor", en el que el Poder Ejecutivo reglamenta lo que dispone el ya citado artículo 120 de la Ley General de Salud, establece en su artículo $1^{\circ}$ lo siguien te: "Declárese de venta libre y en consecuencia pueden ofrecerse al consumidor en cualquier establecimiento comercial, los siguientes medicamentos (...)" (Costa Rica, 2009).

No desconocemos en modo alguno la potestad con que cuenta el Poder Ejecutivo para reglamentar las leyes. Tal potestad es clara pues "solo los órganos autorizados de forma expresa o razonablemente implícitos por la Constitución Política, están dotados de la potestad reglamentaria. La del Poder Ejecutivo deriva de los artículos 140, incisos $3^{\circ}$ y 18, de la Constitución Política” (Jinesta, 2009, p. 260). 
Sin embargo no podemos dejar de anotar que el Poder Ejecutivo, como puede apreciarse en esta norma reglamentaria, lamentablemente se aparta de lo dispuesto por el legislador, ya que no se refiere a establecimientos farmacéuticos, sino que amplía la oferta de medicamentos de venta libre a cualquier establecimiento comercial, dígase en efecto cualquiera, con el grave riesgo que ello implica para la salud pública, tal y como se verá más adelante, incurriendo además en un claro exceso de la potestad reglamentaria.

Debemos referirnos a la ubicación de los reglamentos en el ordenamiento jurídico costarricense, lo que se encuentra establecido en el artículo 6 de la Ley General de la Administración Pública, indicándose en ese cuerpo normativo:

Artículo 6.- 1. La jerarquía de las fuentes del ordenamiento jurídico administrativo se sujetará al siguiente orden:

a) La Constitución Política;

b) Los tratados internacionales y las normas de la Comunidad Centroamericana;

c) Las leyes y los demás actos con valor de ley;

d) Los decretos del Poder Ejecutivo que reglamentan las leyes los de los otros Supremos Poderes en la materia de su competencia;

e) Los demás reglamentos del Poder Ejecutivo, los estatutos y los reglamentos de los entes descentralizados; y

f) Las demás normas subordinadas a los reglamentos, centrales y descentralizados. (Costa Rica, 1978)

Acerca de la potestad reglamentaria, conviene traer a colación lo dispuesto por la Sala Constitucional de la Corte Suprema de Justicia de Costa Rica:

La potestad reglamentaria es la atribución constitucional otorgada a la Administración, que constituye el poder de contribuir a la formación del ordenamiento jurídico, mediante la creación de normas escritas (artículo 140 incisos 3 y 18 de la Constitución Política). La particularidad del reglamento es precisamente el ser una norma secundaria y complementaria, a la vez de la ley cuya esencia es su carácter soberano (sólo limitada por la propia Constitución) en la creación del Derecho. Como bien lo resalta la más calificada doctrina del Derecho Administrativo, la sumisión del reglamento a la ley es absoluta, en varios sentidos: no se produce más que en los ámbitos que la ley lo deja, no puede intentar dejar sin efecto los preceptos legales o contradecirlos, no puede la ley produciendo un determinado efecto requerido por el legislador o regular un cierto contenido no contemplado en la norma que se reglamenta [...] (Costa Rica, 1993).

En similar sentido, el órgano superior consultivo, técnico-jurídico de la Administración Pública en Costa Rica, sea la Procuraduría General de la República ha indicado:

El ejercicio de la potestad reglamentaria consiste en interpretar, complementar, precisar o aclarar la ley que tiene como base, haciendo una mejor comprensión de la misma para hacer posible su verdadera observancia, no obstante que el reglamento se encuentra en un rango 
inferior a la ley. Por ello, los reglamentos no pueden contradecir, ni dejar sin efecto, las disposiciones legales (Costa Rica, 2002).

Así las cosas, ejecutar una ley no es dictar otra ley, sino desarrollarla, sin contrariar su espíritu, pues en este caso el Ejecutivo se estaría atribuyendo la condición de legislador.

Es aquí oportuno señalar que mediante ley de la República se estableció en qué tipo de establecimientos procede la elaboración, manipulación, venta, expendio, suministro y depósito de medicamentos, sea en los establecimientos farmacéuticos, de modo que por vía reglamentaria no se podría contradecir tal precepto, como en efecto se hizo al disponer el decreto de cita que los medicamentos que ahí se declaran de venta libre se pueden ofrecer al consumidor en cualquier establecimiento comercial.

Como se puede ver, se modificó lo dispuesto por el legislador, ampliándose desmedida y peligrosamente - el tipo de establecimientos en los que se ofertan los medicamentos de venta libre.

En conclusión, de lo hasta aquí expuesto no puede derivarse otra cosa más, que una clara violación a los límites de la potestad reglamentaria establecida en el artículo 140 inciso 3 de la Constitución Política costarricense.

No cabe duda que lo referente a los medicamentos de venta libre guarda estrecha relación con la seguridad del paciente y, por ende, con el derecho a la protección de la salud e incluso el derecho a la vida, de obligada tutela por el Estado. $Y$ es que, aunque a tales medicamentos se les atribuye la condición de seguros, no escapan a la posibilidad de generar problemas por empleo inadecuado, precisamente debido a la falta de información o a situaciones en la que éstos podrían significar un riesgo potencial, verbigracia en pacientes con características especiales (niños, ancianos, mujeres embarazadas, madres lactantes y pacientes con enfermedades crónicas como hipertensión, asma, diabetes, epilepsia, insuficiencia renal o hepática, entre otras), en quienes resultan de particular importancia las posibles interacciones entre los medicamentos.

En cuanto al tema de la información, en el caso de los medicamentos de venta libre, bien podría no cumplir su objetivo, esto asociado a diversos factores, por ejemplo al tamaño de la letra de las indicaciones, a la tendencia de las personas a no leer las mismas o bien a su imposibilidad para hacerlo. 
Aquí es importante indicar que la fuente de información idónea por excelencia la constituye el profesional sanitario, en este caso el farmacéutico, quién puede brindar al paciente la información más confiable, comprensible y la que en la gran mayoría de los casos el paciente termina aceptando como válida; información o asesoramiento que, en el caso de Costa Rica, el farmacéutico brinda en forma gratuita y que constituye en gran medida la diferencia entre el éxito y el fracaso del medicamento, para lograr su objetivo sin generar complicaciones.

En abono a lo anterior, se debe señalar que la oferta de medicamentos de venta libre en cualquier establecimiento comercial, tal y como se da actualmente en Costa Rica en virtud de la aplicación del decreto del Poder Ejecutivo antes citado, abre inexorablemente la posibilidad de un almacenamiento no acorde con las condiciones que requieren algunos productos, o la manipulación inadecuada de los mismos por personas inexpertas, situación que inexorablemente implica un riesgo para la población usuaria.

Actualmente la situación descrita persiste en Costa Rica. El Decreto Ejecutivo que permite la venta de estos medicamentos en cualquier establecimiento comercial sigue vigente, pese a que instancias como el Colegio de Farmacéuticos de Costa Rica han advertido de los riesgos para la salud pública que esta situación representa (Costa Rica, 2009).

Fue justamente ese Colegio Profesional el que solicitó a la Procuraduría General de la República un pronunciamiento sobre el particular, emitiendo esa instancia los dictámenes C-172-2009 y C-131-2011, indicando en este último:

Frente a la alegación de seguridad de la dispensa de medicamentos se opone la accesibilidad misma del medicamento. En la medida en que determinados medicamentos que no requieren receta médica y no sean susceptibles de provocar riesgos para la salud puedan ser adquiridos en establecimientos comerciales distintos de los farmacéuticos, se garantiza la accesibilidad de la población a los medicamentos. Aspecto que cobra particular importancia en los lugares alejados de los centros de población e incluso en las poblaciones pequeñas en que no está asegurada la permanencia de una farmacia abierta que pueda vender los medicamentos.

En ese sentido, la imposibilidad jurídica de obtener determinados medicamentos puede implicar que el Estado no brinde la atención y protección adecuada a la salud y, antes bien, que llegue a afectar con su prohibición el derecho a la salud. Es decir, en casos como los indicados en los que las personas no tienen un acceso cercano a los establecimientos farmacéuticos, la prohibición absoluta de venta o expendio de medicamentos de bajo riesgo en lugares comerciales bien podría constituirse en un atentado contra la salud de la persona. [...] (Costa Rica, 2011) 
Puede apreciarse de lo transcrito que la Procuraduría General de la República considera que limitar a las farmacias y botiquines la venta de estos medicamentos comprometería el acceso a estos, afectándose el derecho a la salud.

Si bien coincidimos en que debe garantizarse a la población el acceso al medicamento, no creemos que tal situación se logre sencillamente a través de su venta indiscriminada en cualquier establecimiento comercial, algunos de ellos desprovistas de condiciones sanitarias adecuadas y donde el medicamento es almacenado como cualquier mercancía.

Reiteramos que no discrepamos con la Procuraduría General en cuanto a la importancia del acceso al medicamento. Sin embargo, no se trata del acceso por el acceso, si no más bien de un acceso en condiciones adecuadas que no comprometan ni la seguridad ni la eficacia del medicamento que es adquirido por el paciente. Consideramos tal y, como lo señalamos al inicio, que los medicamentos de libre venta únicamente pueden ofrecerse a la población en establecimientos farmacéuticos debidamente autorizados y registrados, donde se promueva además su uso racional.

Es oportuno indicar que en Costa Rica, por así disponerlo la Ley General de Salud en su artículo 96, todo establecimiento farmacéutico requiere de la regencia de un farmacéutico para su operación, profesional que, por así disponerlo la ley, es responsable de cuanto afecte la identidad, pureza y buen estado de los medicamentos que se elaboren, preparen, manipulen, mantengan y se suministren, de tal forma que en estos establecimientos no solo se garantizan adecuadas condiciones de almacenamiento de los medicamentos de libre venta y buen estado de estos - lo que podría echarse de menos en otros establecimientos comerciales - sino que, además, el paciente cuenta con la posibilidad de recibir información de este profesional de la salud, sobre el adecuado uso de estos medicamentos.

Debemos señalar además que, en nuestro criterio, no se compromete el acceso al medicamento, en este caso a los de libre venta, al determinarse que estos únicamente puedan ofrecerse en establecimientos farmacéuticos, pues en Costa Rica existe una amplia cantidad de farmacias de comunidad privadas (999 farmacias), asimismo de farmacias de la seguridad social (330), según datos proporcionados por la Fiscalía del Colegio de Farmacéuticos de Costa Rica, con cobertura en todo el país.

Expuesto lo anterior conviene comentar que la venta únicamente en farmacias no es una situación extraña en otras latitudes. En España, por así disponerlo la Ley 
29/2006 del 26 de julio del 2006, de Garantía y Uso Racional de los Medicamentos y Productos Sanitarios, en su artículo 2, los medicamentos no sujetos a prescripción médica solo pueden ser dispensados por oficina de farmacia autorizada, con la intervención de un farmacéutico (España, 2006).

Esta es una discusión abierta en Costa Rica. Es justamente a partir del debate y de los aportes de profesionales sanitarios, juristas, instituciones involucradas y de la propia población - pues es claro que no se puede excluir al paciente de lo que le involucra - que pueden alcanzarse acuerdos en un tema que, sin duda, atañe a la salud pública y, por ende, es de interés para el Derecho Sanitario.

\section{Referencias}

COSTA RICA. Ley General de la Administración Pública. 1978.

COSTA RICA. Ley General de Salud. 1978.

COSTA RICA. Decreto Ejecutivo No. 35595-S "Declara Medicamentos de Venta Libre al Consumidor. 2009.

COSTA RICA. Colegio de Farmacéuticos de Costa Rica. Oficio JD-66-2009 del 18 de febrero del 2009.

COSTA RICA. Procuraduría General de la República. Dictamen C-259-2002 del 30 de setiembre del 2002.

COSTA RICA. Procuraduría General de la República. Dictamen C-172-2009 del 19 de julio de 2009.

COSTA RICA. Procuraduría General de la República. Dictamen C-131-2011 del 16 de junio de 2011.

COSTA RICA. Sala Constitucional de la Corte Suprema de Justicia. Resolución No. 243-93 del 19 de enero de 1993.

ESPAÑA. Ley $29 / 2006$, de garantías y uso racional de los medicamentos y productos de interés sanitario. 2006

JINESTA LOBO, Ernesto. Tratado de Derecho Administrativo. Tomo I. (2 ed.) San José, Costa Rica : Editorial Jurídica Continental, 2009. 595 p. ISBN 978-9968-784-863.

Recebido para publicação em 5 de maio de 2014. Admitido para publicação em 18 de junho de 2014. 